\title{
COORDINATION GUIDELINES FOR VIRTUAL DESIGN AND CONSTRUCTION
}

*Anoop Sattineni \&Kyle Mead Auburn University

118 M. Miller Gorrie Center

Auburn University, Auburn, AL, 36849, USA

(*Corresponding author: sattian@auburn.edu) 


\title{
COORDINATION GUIDELINES FOR VIRTUAL DESIGN AND CONSTRUCTION
}

\begin{abstract}
Over the past decade the use of BIM in the AEC industry has grown several fold and with it the number of standards available for implementing BIM. The 'National BIM Standard' by buildSmart Alliance, the 'Contractor Guide to BIM' by the Associated General Contractors of America, the 'BIM Project Execution Planning Guide and Templates' from Penn State University, the 'BIM Roadmap' by the US Army Corps of Engineers are some of the several BIM guidelines that are currently available to the AEC industry practitioners. Some of these guidelines are as comprehensive as defining BIM and the associated taxonomy while others are meant to be used on an individual project basis. From a contractor's perspective one of the key benefits of using BIM is for the purpose of collision detection and coordination. This research has found that currently available guidelines do not address these issues adequately. For instance, the currently available guidelines do not allow the subcontractor to quickly communicate issues such as naming conventions and color schemes within the model, to the general contractor. Consequently general contractors and sub-contractors find themselves making changes to their BIM deliverables based on each other's abilities and levels of adoption, apart from reason's stemming from use of different software platforms. This paper describes how a group of contractors and subcontractors from Atlanta and Birmingham in the United States came together to create and adopt a 'Coordination Guidelines for Virtual Design and Construction'. These guidelines were specifically created with the purpose of streamlining the construction coordination process using BIM. This paper describes how the guidelines created differ from other guidelines currently available in the industry.
\end{abstract}

\section{KEYWORDS}

Coordination Guidelines, BIM Guidelines, BIM Standards, Virtual Design and Coordination.

\section{INTRODUCTION}

Over the course of the past 10 years, the Architecture, Engineering, and Construction industry has experienced the transformative effects due to the introduction of Virtual Design and Construction (VDC) tools. This latest technological shift is in-line with what the industry experienced with the introduction of Computer Aided Design during the mid-1980's in that it has the potential to dramatically improve process efficiencies, accuracy, and understanding of design documents, when harnessed properly (Howard et al., 1989). The key difference is that this time, the technology is far-reaching, capable of transforming information exchange processes(Denzer \& Hedges, 2008). VDC processes and tools have the potential to improve the notoriously inefficient processes of the industry by reducing re-work, streamlining the transfer of information, enhancing understanding, and improving accuracy(Azhar et al., 2008). These are only a few of the purported benefits of VDC, and as the technology evolves and user expertise increases, so too will the advantages of virtual design and construction.

Building Information Modeling is a single element within the larger framework of Virtual Design and Construction (VDC). While BIM refers to the digital models that represent the forefront of 3D representation in building design today, VDC includes a larger framework of processes including 4D and 5D analyses, which represent time and cost respectively. VDC can also encompass a number of other available tools, including 3D scanning technology, Radio Frequency Identification (RFID) tracking technology, and end-user Facilities Management and Building Automation and Management Systems (BAS / BMS). VDC tools, and particularly BIM tools are available in a wide array of technologies and 
software/hardware tools, and can be incorporated into a diverse spectrum of project settings and team arrangements, and building types and scopes of work. However, while VDC provides a large framework of tools for a variety of needs, BIM is primarily intended to facilitate building design and coordination, enhance communication, and identify and solve construction conflicts prior to them reaching the field, thereby saving time on the construction schedule. BIM is not a process, but rather a tool; Similar to how a carpenter needs a square to complete a successful woodworking project, the modern building designer needs a BIM to complete a successful VDC project.

Today, users are faced with an abundance of tools at their disposal and wide ranging industry standards on how to use those tools. The AEC sector is shifting towards an industry where a VDC process seems to be well on its way to adoption, judging by user statistics(Jung \& Joo, 2011). This paper will focus on examining Building Information Modeling, both from a historical context, as well as current uses and practices. There are many documents that are available today for BIM users to use reference tools. This paper will examine a selection of these documents. Specifically this paper presents various implementation issues that are addressed in each of these documents. Finally, this paper will present a new document that was created by a group of contractors in the South-eastern United States, and that is aimed at addressing many of the shortcomings found in the currently available documents.

\section{Historical Perspective of BIM}

Building Information Modeling (BIM) is the process of creating and using digital models for design, construction, and operations of projects (McGraw-Hill, 2009). BIM originated and has evolved from two-dimensional Computer Aided Drafting (CAD) tools. 2D-CAD tools were developed for personal computers starting in the mid 1980's for a variety of uses including manufacturing and building design. Around this time, a number of software companies were developing competing products, including the American firms AutoDesk and Bentley Technologies, who remain the top firms in this field today (Watson 2010). During the mid-1980's, 2D drawing tools were the only form of computerized drafting technology commercially available to designers. In 1982, AutoDesk introduced AutoCAD, and three years later, Bentley Technologies released a program called MicroStation that allowed 2D computerized drafting. It would take another decade for the software developers to begin to incorporate three-dimensional, parametric capabilities (Watson 2010).

During the mid 1990's, a number of companies were developing 'object-based' modeling tools including Charles River Software. Object-based modeling refers to computerized models based on threedimensional forms with intelligent information, rather than orthographic line drawings. This is a dramatic departure from 2D drafting because model components have identities such as walls, floors, or roofs, rather than simply using lines to represent these things. Charles River Software would later go on to rename themselves Revit Technology, prior to be acquired by AutoDesk in 2002 for $\$ 133$ Million (Watson 2010). AutoDesk's primary competitor, Bentley was developing similar technology throughout the course of the mid to late nineties.

Technological developments have taken standard 2D drafting tools and added parametric capabilities to them. Parametric models use mathematical equations and geometric constraints to apply parameters to the shapes and spaces being designed in the digital environment. Parametric models are based on integrated geometric relationships that are bound by rules and are non-redundant (Eastman et al. 2011). These technologies have been evolving for the last 3 decades, but BIM as we know it currently began emerging in the mid 2000's(Watson 2010). Products such as Bentley Architecture V8.1 and Revit Architecture 2013 represent the latest achievements in parametric modeling. These tools allow users to create object-based models with intelligent components. That means that users have a palette of solid forms at their disposal, such as walls, columns, ducts, or doors. Instead of drawing these items individually with line-work, the software provides solid-state modeling that enables the user to create models comprised of intelligent building components. Building systems can be modeled, modified, and rendered internally using the modeling and rendering engines within the software (Eastman et al. 2011). 


\section{EXECUTING THE BIM PROCESS}

Typically, a BIM refers to one single model that represents the overall virtual design of a building. Within this model may reside other models, each specific to a certain scope of work such as electrical systems, plumbing piping, mechanical equipment, structural frame, or architectural elements. Each of these individual models is 'linked' together so that the individual files can be viewed and compared as a composite. In that regard, these models can be very complex, and proper file management is an important aspect of the process. The typical team that assembles, uses, and coordinates all of these different models into one conglomerate that can be used for overall building uses can be very large and complex. However, in general, the team usually consists of the Architect and their team of consulting engineers, typically the Mechanical, Electrical, and Structural consultants, at a minimum. Other participants include the General Contractor, and their team of sub-contractors, including structural and MEP contractors.

BIM has many added benefits for building designers and constructors. Currently, industry professionals use BIMs for a range of purposes that impact design, preconstruction, construction, and facilities management processes. Models can be used to spatially coordinate overlapping scopes of work in tight spaces, something that previously had been a time-consuming field operation. BIM can test scheduling logic and highlight constructability and site logistics issues. It can be used to create photo realistic renderings that enhance our understanding of design intent. It can create a dialogue between design documents and estimating processes by producing building material quantities and interfacing with estimating software. And it can be employed by facilities managers to better understand the pieces and parts of their buildings and how they work and should be maintained. This list is not exhaustive, but represents the broad application and significant power of BIM tools. According to a 2012 market survey conducted by McGraw-Hill, 66\% of respondents claimed improved project processes due to the use of BIM on projects (McGraw Hill 2012).

BIM has considerable process implications for Architects. Because of the parametric nature of BIM, when an architect models a building assembly, sections and details are instantly drafted. Because of the intelligence built into the programs parametrically, many views of a single assembly can be created through one drafting effort, rather than the traditional efforts aimed at plan, section, elevation, detail, etc. This means that labor efforts are added to the schematic design phase, but also that at the completion of schematic design; the team has a model that is rich in information. Up to 2 out of 3 architects consider the greatest value derived from BIM to be the reduction in rework during the design development phase of the project (McGraw Hill 2012).

The next important thing BIM provides for Architects is a means of communicating design intent in a way previously unavailable. BIM software is equipped with rendering engines that are capable of producing photo-realistic renderings of both interior and exterior surfaces and spaces. Where the Architect was previously confined to using the traditional monotone plans, sections, and elevations, through BIM, full-color, three-dimensional images with materiality can be provided. Photo realistic rendering allows architects to communicate their design intent to Owner's to help inform design decisions, as well as Contractors to ensure that pricing and scheduling efforts are as accurate as possible. This ability has fundamentally changed the way Constructors are able to understand and plan for Architectural design.

Aside from enhanced understanding of design elements, BIM provides Contractors with many other tools. Perhaps the most important is the ability to coordinate complex building systems that interface with one another. Mechanical, Electrical, Plumbing, Fire Protection piping, and other building services typically are located within ceilings, walls, and other confined spaces. As such, they typically require considerable coordination to ensure they all fit and function properly. Prior to BIM, this process occurred in the field, by the contractors, and typically led to an abundance of Requests for Information (RFI) and Supplemental Instructions from the design team. These RFI's led to rework and delays that are costly to projects. A majority of respondents to McGraw Hill's SmartMarket Survey indicated that they believed that BIM allowed users to reduce omissions and errors in design documents, which leads to less re-work (McGraw Hill, 2009). With BIM, interfacing trade contractors can gather together prior to a single shovel 
of dirt being moved and work these conflicts out in the virtual realm. This not only avoids the inefficient process of seeking clarifying information in the field, but also helps to avoid costly work stoppages and redesigns.

In addition to resolving field conflicts and eliminating RFI's, BIM is being used considerably by contractors in 4D analysis. 4D analysis is generally accepted as the ability to tie sequencing of activities on from construction project schedule to the objects in the model. This allows construction professionals to visualize exactly how the building will be erected. This ability to visualize how the project will be sequenced allows builders to test their scheduling logic, critical path, and uncover otherwise unforeseen conditions that may relate to site logistics or unique environmental conditions. It also avails the contractor with the ability to communicate to owners, architects, and specialty contractors their plan for erecting the structure.

Lastly, BIM can provide building and facilities managers with tools to better manage their properties. If stipulated by the contract, intelligent information can be added to the working model produced by the design and construction team. This information serves to replace the cumbersome 'Operations and Maintenance' manuals that the design and Construction team typically hand over to the Facilities Manager at the conclusion of the project. Information including maintenance schedules, manufacturer's contact, warranty information, and replacement parts can all be linked within the model. Furthermore, if designed, Building Automation Systems and Building Management Systems can be linked to the BIM, which can provide the Facilities Manager with an alert if something in their facility is functioning improperly, such as a duct leaking, a burned out lamp, or a door lock malfunction. The ability to virtually design and construct the building is leading to the ability to virtually manage the building as well. This final capacity of BIM is probably the least developed, but has perhaps the most promise to the future value of the technology.

Currently, there is no standard way to execute Virtual Design and Construction processes on building projects. The level of detail, parties involved, and extent of coordination and modeling is a factor of the building complexity and contract requirements. There are many variables that each project team needs to consider in order to define what approach is best suited for their needs. Some of these variables include whether or not to incorporate BIM efforts into the contract, what software to use, and what to do with the model once the construction has completed. Furthermore, the team must consider the roles, responsibilities and deliverables of all members of the interfacing teams. For example, it is common today for the Architecture and Engineering team to produce one model, and for the Construction manager and Specialty Contractors to develop their own model based on the information provided to them. This inefficiency is due to ambiguity relating to authorship and ownership requirements and legalities concerning the model as legal document. Using VDC processes on a construction project can add substantial value to the job. However, the lack of current industry-wide best practices for these new processes is resulting in inefficient processes, duplicate efforts, and legal and liability anxieties.

\section{BIM EXECUTION PLANS, GUIDES, STANDARDS, AND RELATED DOCUMENTS}

As VDC processes and tools continue to gain momentum within project teams, the need for standardizing processes has arisen. However, standardizing a process that is so wide-reaching, complex, varied, and subjective presents obvious challenges. A variety of groups have worked towards producing documents and guides that aim to define and standardize VDC processes. Most of these documents are large (over 50 pages), and far-reaching; the documents attempt to tackle every aspect of the use of the various VDC processes and tools available. For example, many of the available BIM execution guides attempt to standardize process management, technical procedures, software and hardware, and roles and responsibilities. Table 1 shows some of the organizations that have produced documents that address BIM from an industry standpoint. VDC has grown to the point where it is being used on a widespread basis in the American Construction industry (McGraw Hill 2012). These tools and processes have evolved rapidly, to the point where the majority of major firms are using a variety of BIM tools and 4D and 5D technologies. Academia has followed suit by producing a number of studies, papers, and examinations of how the tools 
work, how they can be used, and how they are changing the industry. These documents are important for cementing the understanding of the benefits of VDC for users, but not useful for improving performance when using VDC. Despite rapid growth and embrace from the industry, there continues to be inefficiencies and waste in these new processes. Because of the lack of industry standards or best practices, the difference in protocol between different firms and firms across different regions can be substantial. These discrepancies cause users to experience large amounts of non-productive time.

In addition to these industry groups and academic institutions, nearly every large General Contractor and Architecture firm that is using these tools has developed a document to use for their own projects that illustrates the process of using BIM on a construction project. The variety and depth of the materials and media available for BIM standards is in a rapidly growing phase. Most of the documents that have been produced can be characterized as reference guides or standards. They are wide reaching guides that exist to serve as reference material, comparable to the books available for software support.

Table 1. Organizations Publishing BIM Standards Organization

AGC - The Associated of General Contractors of America (AGC, 2010)

GSA - The General Services Administration (GSA, 2012)

USACE - The United States Army Corps of Engineers (USACE, 2012)

NIBS - National Institute of Building Sciences (buildingSMART, 2012)

PSU - Penn State University (Penn State, 2012)

The construction management program at XXX University invited a group of industry experts in BIM to seek advice about pedagogical issues as well as provide these professionals an opportunity to interact with one another to discuss the changing landscape of VDC. The group included industry BIM professionals representing specialty sub-contractors as well as general contractors from several areas of the South-eastern United States, mainly Birmingham, Alabama and Atlanta, Georgia. Several of these industry professionals were also recent graduates of the program. At one of these meetings to discuss the challenges and opportunities in their professional roles, the group pointed out that while they work with one another on several projects, they find themselves having to adjust their processes and procedures with each of them. An initial meeting illuminated the fact that many of these graduates were facing the same issues and hurdles trying to work with VDC tools at the professional level. This lead to the group agreeing to create a document that might help them streamline the processes of using BIM in a collaborative environment with one another. Issues of standardization, coordination, technical operability and such were a common thread amongst all of them. Over the course of the following 6 months and several meetings, involved more stakeholders, and shared more ideas about the state of BIM in the industry within the South-eastern region. The culmination of these open forums was the goal to craft a document that the professionals in the room could use to standardize coordination and BIM project processes; making individuals and workflows more efficient was the chief aim of this task.

The group of professional contractors, specialty contractors and researchers was named the "BIM Contractors Advisory Group" and entitled the document "Coordination Guidelines for Virtual Design and Construction'. The document exists as a standard for professionals to use to streamline setting up BIM projects, and more importantly, understanding how exactly to execute the coordination of different people's virtual modeling. Version 1.0 of this document was created in the January-2012 and is being used by contractors in the area since then. Early discussions with these contractors indicate positive response to the implementation of this document.

Next, this document is specific. It is not a general reference guide; rather it is a procedural document that defines exactly how coordination processes are to occur on a Virtual Design and Construction project. These procedures were based on the closest thing to 'best practices' that exist today: the processes by which designers and builders are using BIM with one another within a region. This document explicitly lays out things like team member names and contacts, roles and responsibilities, team goals, definitions, file naming and organizing conventions, and other technical information. It standardizes modeling 
practices such as layer naming conventions, file sharing procedures, the colors for scope items, precoordination requirements, and clash detection meeting procedures. Most teams using BIM today do all of these things in a slightly similar manner, but with enough variation that the differences cause notable slowdowns when individuals kick-off a new project with a new teammate. The idea behind the document was to create a set of standards that focus on specific procedures, and to standardize those procedures within a region in a manner such that it reduces or eliminates the inefficiencies that are currently inherent with the startup phase of a BIM project.

The guides and handbooks available for BIM execution are largely for industry participants who are new to the process. They explain how the parties should be arranged, what the tools are and what they are capable of, and how teams can derive value and benefit from their varied uses. However, there is a gap in explicitly examining and standardizing how teams can work together, how to do it well, and how to do it efficiently. In defence of the existing guides, the trouble with trying to capture, address, and standardize BIM on a large scale is that every project, and every team, is going to approach the process differently. Just as Architects, Contractors, and Engineers practice their disciplines differently amongst regions and countries, BIM is no different. Creating a document that attempts to place national or even international standards or codes on something this complex is bound to be too rigid. It may not be able to accommodate the specifics of individual team dynamics or unique aspects of project conditions.

Table 2 - BIM Guidelines and Standards

\begin{tabular}{|c|c|c|c|}
\hline Organization & Title & Year & Pages \\
\hline $\begin{array}{l}\text { Associated General Contractors of } \\
\text { America }\end{array}$ & The Contractors Guide to BIM & $2010-\mathrm{V} 2.0$ & 48 \\
\hline $\begin{array}{l}\text { Governmental Services } \\
\text { Administration }\end{array}$ & GSA BIM Guide Series & 2012 & $450+$ \\
\hline $\begin{array}{l}\text { National Institute of Building } \\
\text { Sciences }\end{array}$ & $\begin{array}{l}\text { United States National Building } \\
\text { Information Modeling Standard }\end{array}$ & $2012-\mathrm{V} 2.0$ & 183 \\
\hline Penn State University & $\begin{array}{l}\text { BIM Project Execution } \\
\text { Planning Guide }\end{array}$ & $2010-\mathrm{V} 2.1$ & 134 \\
\hline US Army Corps of Engineers & $\begin{array}{l}\text { Building Information Modeling } \\
\text { Roadmap }\end{array}$ & 2012 & 55 \\
\hline $\begin{array}{l}\text { Southeast - Virtual Design \& } \\
\text { Coordination Guidelines }\end{array}$ & $\begin{array}{l}\text { Coordination Guidelines for } \\
\text { Virtual Design and } \\
\text { Construction Projects }\end{array}$ & 2012 & 12 \\
\hline
\end{tabular}

The title and the associated organization that produced each of these organizations is shown in table 2. The shear size of each of these documents can be daunting in trying to implement on every project, as shown in table 2. While BIM is widely acknowledged as a recent change in the AEC industry over the past ten years, there have already been multiple iterations of guidelines and standards. By examining the page counts and major topic headings, it quickly becomes apparent that these documents are intended to examine BIM from a big-picture point of view. The documents focus on explaining the history of BIM, the theory of its use, how firms can adopt and gain value from BIM, and how BIM processes can be implemented.

Table 3 shows the big picture issues that are addressed in each of these documents. Most of the available guidelines, specifications, and standards have been crafted as reference tools. They explain how BIM works so that novice users can understand the processes and decide what level to implement them within their own firms. The target audience is the new BIM user seeking an understanding and introduction to BIM, not the experienced user seeking efficiency in their daily processes. Furthermore, many of these documents are not project centric - they do not delve into specific procedures, both from a team/coordination standpoint, as well as a technical and technological standpoint. They are process centric, and as such have an important role in the available literature, but are ultimately ineffective for experienced project teams. 
Table 3 - BIM Guidelines and Standards -A

\begin{tabular}{lcccc}
\hline Organization & $\begin{array}{c}\text { BIM History/ } \\
\text { Background }\end{array}$ & $\begin{array}{c}\text { Information } \\
\text { Exchange Processes }\end{array}$ & $\begin{array}{c}\text { BIM } \\
\text { Theory }\end{array}$ & Interoperability Issues \\
\hline AGC & $\mathbf{X}$ & $\mathbf{X}$ & $\mathbf{X}$ & $\mathbf{X}$ \\
GSA & $\mathbf{X}$ & $\mathbf{X}$ & $\mathbf{X}$ & $\mathbf{X}$ \\
NIBS & $\mathbf{X}$ & $\mathbf{X}$ & $\mathbf{X}$ & $\mathbf{X}$ \\
PSU & $\mathbf{X}$ & $\mathbf{X}$ & $\mathbf{X}$ & $\mathbf{X}$ \\
USACE & $\mathbf{X}$ & $\mathbf{X}$ & $\mathbf{X}$ & $\mathbf{X}$ \\
Southeast & & & & $\mathbf{X}$ \\
\hline
\end{tabular}

Table 4 shows how each of these documents address project specific issues where the various subcontractors and contractors can collaborate using BIM tools.

Table 4 - BIM Guidelines and Standards - B

\begin{tabular}{|c|c|c|c|c|c|}
\hline Organization & $\begin{array}{l}\text { Project Team } \\
\text { Information }\end{array}$ & $\begin{array}{l}\text { Meeting } \\
\text { procedures, file } \\
\text { formats, model } \\
\text { colors, etc. }\end{array}$ & $\begin{array}{l}\text { Project Goals \& } \\
\text { Responsibility } \\
\text { Matrix }\end{array}$ & $\begin{array}{l}\text { Specific } \\
\text { Technical } \\
\text { Guidelines \& } \\
\text { Procedures }\end{array}$ & $\begin{array}{l}\text { Order of } \\
\text { Precedence } \\
\text { for Scopes of } \\
\text { Work }\end{array}$ \\
\hline$\overline{\mathrm{AGC}}$ & $\bar{X}$ & & $\bar{X}$ & & \\
\hline \multicolumn{6}{|l|}{ GSA } \\
\hline NIBS & & & & & \\
\hline PSU & $\mathbf{X}$ & & $\mathbf{X}$ & & \\
\hline USACE & $\mathbf{X}$ & $\mathbf{X}$ & $\mathbf{X}$ & $\mathbf{X}$ & \\
\hline Southeast & $\mathbf{X}$ & $\mathbf{X}$ & $\mathbf{X}$ & $\mathbf{X}$ & $\mathbf{X}$ \\
\hline
\end{tabular}

\section{CONCLUSIONS}

This new document is notable for a number of reasons. There are three main characteristics of it that make it noteworthy: It is collaborative, it is specific, and most importantly, it is hierarchical. The document was authored with the intention of being a working document that firms across the region could use, become familiar with, and employ to improve the efficiency of coordination procedures on construction projects. It is intended to be a project-centric working document that can adapt easily and not cumbersome to use, two challenges that many of the larger documents presented.

Industry associations or groups produced many of the available standards, guides, and documents for executing BIM on design and construction projects with input from users. The 'Coordination Guidelines for Virtual Design and Construction' was authored by everyday users of BIM applications. Furthermore, while many of the other documents were produced by representative of one stakeholder group (such as contractors, owners, or architects), this document was created by a roundtable made up of a diverse group of individuals. These include general contractors, specialty contractors, and academics - each with an equal voice and an equal opportunity to weigh-in and contribute input to the documents. The result is a document that users have buy-in with; the document has been crafted in a manner such that it focuses and highlights only the areas that are important to the teams who will be using it. This allows the document to be streamlined and devoid of much of the ancillary information that does not directly contribute to teams achieving their goals.

Finally, this document is unique because it assigns a hierarchy to the elements that are commonly modeled and coordinated within a BIM. Most individual General Contractors, Architects, and Specialty Contractors today have their own internal order of precedence that they follow for virtual modeling. Because of the lack of common understanding of where scope items fit within building spaces, coordination efforts can be grossly exacerbated. For example, if the electrical contractor is unaware of gravity fed piping in a corridor ceiling, they may model their raceways tight to the structure above. Then, when it comes time to coordinate their model with the plumbing contractor, they find that the plumber needs this space for waste piping in order to get the proper slope. This results in considerable added work 
whereby the electrical contractor must now re-model the raceways and then re-coordinate the two models. If there was a common understanding of the order of precedence for model components, considerable time could be saved. This document provides users with that hierarchical framework, whereby at project kickoff, each of the team members is given a list identifying which scope items have the highest priority (in the example, waste piping), which in turn defines which items will need to move to accommodate the higher priority items. This order of precedence was agreed upon by all of the stakeholders involved in drafting the document, and should help to expedite pre-coordination efforts between 1-2 trades, as well as make team-wide coordination efforts amongst all trade models more efficient.

\section{REFERENCES}

AGC, 2010. The Contractor's Guide to BIM - 2nd Edition | Building Material | AGC - The Associated General Contractors of America. Available at: http://newsletters.agc.org/buildingmaterial/2010/02/15/the-contractors-guide-to-bim-2nd-edition/ [Accessed February 17, 2013].

Azhar, Salman, Hein, M. \& Sketo, B., 2008. Building information modeling (BIM): Benefits, risks and challenges. In Proceedings of the 44th ASC National Conference. Auburn, AL.

buildingSMART, A., 2012. National BIM Standard - United States. Available at: http://www.nationalbimstandard.org/ [Accessed February 17, 2013].

Denzer, A.S. \& Hedges, K.E., 2008. From CAD to BIM: Educational Strategies for the Coming Paradigm Shift. In AEI 2008. American Society of Civil Engineers, pp. 1-11. Available at: http://ascelibrary.org/doi/abs/10.1061/41002\%28328\%296 [Accessed February 17, 2013].

Eastman, C. et al., 2011. BIM Handbook: A Guide to Building Information Modeling for Owners, Managers, Designers, Engineers and Contractors, John Wiley \& Sons.

GSA, 2012. 3D-4D Building Information Modeling. Available at: http://www.gsa.gov/portal/content/105075 [Accessed February 17, 2013].

Howard, H. et al., 1989. Computer Integration: Reducing Fragmentation in AEC Industry. Journal of Computing in Civil Engineering, 3(1), pp.18-32.

Jung, Y. \& Joo, M., 2011. Building information modelling (BIM) framework for practical implementation. Automation in Construction, 20(2), pp.126-133.

McGraw Hill, 2012. Business Value of BIM, Available at: http://images.autodesk.com/adsk/files/business_value_of_bim_for_infrastructure_smartmarket_re port_2012.pdf [Accessed February 17, 2013].

Penn State, 2012. BIM Execution Planning. Available at: http://bim.psu.edu/Project/resources/default.aspx [Accessed February 17, 2013].

USACE, 2012. USACE BIM Roadmap. Available at: https://cadbim.usace.army.mil/default.aspx?p=a\&t=1\&i=13 [Accessed February 17, 2013].

Watson, A., 2010. BIM - A Driver for Change. In Proceedings of the International Conference on Computing in Civil and Building Engineering. 